\title{
ЭЛЕКТРОЭНЦЕФАЛОГРАФИЧЕСКИЕ КОРРЕЛЯТЫ У ЗДОРОВЫХ ЮНОШЕЙ ПРИ РАЗЛИЧНЫХ ЭМОЦИОГЕННЫХ ВОЗДЕЙСТВИЯХ
}

\author{
${ }^{1}$ Казымов А.Г., ${ }^{1}$ Джафарова С.Ш., ${ }^{1}$ Казымова Л.А., ${ }^{1}$ Алиева Д.М., ${ }^{2}$ Гасанов Х.И.* \\ ${ }^{1}$ Кафедра нормальной физиологии Азербайджанского Медициского Университета, Баку, Азер- \\ байджан; \\ ${ }^{2}$ Республиканская клиническая больница им. акад. М.А.Мир-Касимова, Баку, Азербайджан
}

\begin{abstract}
Настоящая работа посвящена изучению особенностей ЭЭГ в возрастном аспекте у здоровых юношей 17 и 18 лет, в спокойном состоянии и при различных эмоциогенных воздействиях. Показано, что у юношей 17 и 18 лет в условиях физиологического покоя, умственной нагрузки, отрицательного и положительного эмоционального состояний интегральные ЭЭГ - характеристики (показатели процентной представленности, спектральной мощности, частотно-амплитудного анализа) имеют как выраженное сходство, так и специфические особенности. В частности, при различных функциональных состояниях обнаруживается достоверная смена альфа-ритма на тетаритм, максимально выраженная, в основном, при напряженном состоянии и умственной нагрузке.

Ключевые слова: электроэнцефалография, здоровые юноши, эмоциогенные воздействия.
\end{abstract}

Функциональное состояние (ФС) ЦНС рассматривается как интегральное понятие, представляющее результат сложнейшего взаимодействия организма как целого с внешней средой, а также результат чрезвычайно сложного внутрицентрального взаимодействия отдельных нейронов, их ансамблей, разных уровней ЦНС, её различных структур $[4,5,9,13]$. Различные ФС формируются за счет множества факторов, среди которых особо следует выделить возраст, индивидуальные генетические особенности ЦНС, мотивационные компоненты [6, 23, 26, 29]. Интегративаная деятельность мозга, лежащая в основе когнитивных процессов, базируется на сложной динамической организации отдельных структурных образований, объединенных различными по характеру функциональными связями $[2,8,9,17,28]$.

Оценивание пространственной организации корковой ЭЭГ является одним из наиболее перспективных подходов к изучению интегративной деятельности мозга человека. Особый интерес при этом представляют методы анализа совокупной согласованности одновременно нескольких или многих отведений ЭЭГ, направленные на изучение целостной организации коркового биоэлектрического поля [9, 10].

На фоне высокого уровня психоэмоционального напряжения обнаруживаются признаки межполушарной функциональной асим- метрии в ЭЭГ, которая сглаживается по мере адаптации к заданию $[4,18,31]$. В последнее время появились новые данные о выраженности и функциональной значимости $\delta$-активности в ЭЭГ здорового бодрствующего человека. Отмечено [25] появление диффузного $\delta$-ритма при интеллектуальной деятельности: наблюдается рост мощности $\delta$-ритма при выполнении тестов разной сложности и мысленных задач [30].

Физиологически покой занимает лишь определенную часть континуума бодрствования, и весьма важно для изучения реактивности головного мозга практически здорового человека в разные возрастные периоды его развития при разных ФС. Все вышесказанное не оставляет сомнений в том, что изучение интегративной деятельности мозга в покое, при функциональных нагрузках, на разных этапах юношеского возраста, особенно в постпубертантном, является одной из важных проблем современной возрастной физиологии и медицины [19].

Основной целью данной работы является изучение в возрастном аспекте интегративной деятельности мозга у практически здоровых юношей (17-18 лет) при различных функциональных состояниях.

Методы и материалы исследования. Нами проведены исследования 28 практически здоровых юношей в возрасте 17-18-лет. Регистрацию биоэлектрической активности (ЭЭГ)

*e-mail: doctorxanlar@yahoo.com 
осуществляли монополярным способом от $\left(\mathrm{F}_{3} \mathrm{~F}_{4}\right),\left(\mathrm{C}_{3} \mathrm{C}_{4}\right)$ и $\left(\mathrm{O}_{1} \mathrm{O}_{2}\right)$ обоих полушарий головного мозга, расположенных по международной схеме 10-20 на 8- и 16-канальном электроэнцефалографах фирмы "Нейрон-Спектр" и "Медикор" при различных функциональных состояниях (ФС): спокойном, напряженном, отрицательно- и положительно-эмоциональном.

Спокойное состояние испытуемых записывалось после предварительной 15-20-ти минутной адаптации в затемненной камере, при расслабленном бодрствовании, полулёжа, с закрытыми глазами. Напряженное состояние создавали моделированием умственной нагрузки - счет в уме (решение арифметических задачи различной степени сложности). Моделирование ОЭС (отрицательное эмоционального состояния) осуществлялось посредством словесного порицания. ПЭС (положительное эмоциональное состояние) моделировалось посредством поощрения за хорошие знания.

Постоянное время записи ЭЭГ равнялась 0,3 сек при фильтрах 30 , колибровычный сигнал 50 мкВ при отклонении регистратора от изолинии на 7 мм. Безартефактные отрезки записи ЭЭГ с 6-и исследуемых зон коры вводились в компьютер. В течение 20 с. записывали фон и в течение 40 с. - функциональное состояние. Спектральный анализ доминирующего ритма $\alpha$-диапазона проводили с помощью пакета автоматизированной обработки "Brainsys". Спектральную мощность (мкВ) ?-ритма рассчитывали на основе Фурьепреобразования. Эпоха анализа - 8 с. Дополнительно для каждой области регистрации ЭЭГ рассчитывали долю (в \%) спектральной мощности $\left(\right.$ мкB $\left.^{2}\right)$ - дельта $(\delta)$, тета $(\theta)$, альфа $(\alpha)$ и бета $(\beta)$ и суммарной мощности (по всем эпохам анализа), статистическую значимость их динамики рассматривали индивидуально. Вычислялись процентная выраженность для каждого диапазона частот - $\delta, \theta, \alpha$ и $\beta$ ритма. Для амплитудно - частотного анализа была использована многомерная ЭЭГ, которая вводилась в ЭВМ с выхода магнитографа при режиме off-line посредством аналогово-цифрового преобразователя. Для вычисления плотности спектра мощности применена процедура Блекмана-Тъюни.

Все показатели, полученные в результате исследований, обрабатывались в соответствии с критериями Стьюдента- Фишера.

Результаты исследований. Особенности процентной представленности основных ритмов. Процентная выраженность $\alpha-, \beta-, \theta-$ и $\delta$-ритмов в изучаемых областях головного мозга юношей 17-ти лет в спокойном состоянии показана в табл. 1. В напряженном состоянии, по сравнению со спокойным, отмечалось увеличение процентной представленности $\alpha$-ритма в исследуемых областях. Выраженность $\beta$-ритма снижалась в левой и правой лобной, в тоже время отмечено увеличение в правой центральной области. Процентность же $\theta$-ритма увеличивалась в левой и правой лобной, а в правой центральной областей отмечалось снижение. С другой стороны, отмечалось увеличение выраженности $\delta$ ритма в левой и правой лобной областях, а в левой и правой центральной и правой затылочной областях наблюдалось снижение процентности $\delta$-ритма.

У юношей 18-ти лет, по сравнению с 17летними, в спокойном состоянии наблюдалось снижение процентной представленности $\alpha$-ритма в левой лобной и правой затылочной областях, $\beta$-ритм с увеличивался в левой и правой лобной, в то время как в левой и правой центральной областях отмечено снижение (таб.2).

У 18-тилетних юношей в напряженном состоянии, по сравнению со спокойным, отмечалось увеличение процента $\alpha$ - ритма в левой и правой лобной и в левой центральной областях. Наблюдается увеличение процентности $\beta$-ритма в левой лобной, $\theta$-ритма в левой и правой лобной, центральной и в правой затылочной областях. В то же время наблюдалось снижение $\delta$-ритма в левой и правой лобной, а в левой центральной области отмечено увеличение $\delta$-ритма.

При исследовании 18-летних юношей в напряженном состоянии наблюдалось снижение процента $\alpha$-ритма в левой лобной области, в то время как в левой и правой централь- 
ной областях отмечено увеличение его. Изменение $\beta$-ритма было выражено снижением его процентности в правой лобной области. В $\theta$ ритме достоверного изменения в процентах не наблюдалось. В левой центральной области отмечено увеличение процента $\delta$-ритма (таб.2).

При ОЭС у 17-тилетних юношей, по сравнению со спокойным, увеличилась процентность $\alpha$-ритма в правой лобной, правой центральной и левой и правой затылочной областях. У $\boldsymbol{\beta}$-ритма наблюдалось снижение в левой и правой лобной и центральной областях. У $\delta$-ритма наблюдалось снижение его процентности в левой и правой затылочной областях. У 18-тилетних юношей при ОЭС, в сравнении со спокойным, отмечалось увеличение процентной представленности $\alpha$-ритма в левой лобной, в левой и правой центральной областях.

Отмечено процентное увеличение $\beta$-ритма в правой затылочной области, а увеличение $\theta$-ритма наблюдалось в левой и правой лобной, центральной, и затылочной областях. У $\delta$-ритма отмечено снижение процента в левой и правой лобной, а также в правой центральной областях.

В возрастном аспекте у 18-тилетних, по сравнению с 17-тилетними, при ОЭС отмечалось увеличение процента $\alpha$-, и $\beta$-ритма в правой затылочной области. У $\theta$-ритма наблюдалось снижение процента его в левой и правой лобной областях (таб.2).

При ПЭС у 17-тилетних отмечалось увеличение процента $\alpha$-ритма в левой и правой лобной и затылочных областях. $\theta$-ритм увеличивался в левой и правой лобной, а в правой центральной области отмечалось снижение. У $\delta$-ритма отмечено снижение его выраженности в левой лобной и левой и правой затылочной областях (таб.1). У 18-тилетних юношей, по сравнению со спокойным состоянием, выявлялось увеличение процентности $\beta$-ритма в левой и правой лобной, а также в левой центральной областях. У $\delta$-ритма отмечалось снижение процента в левой и правой лобной, а также в правой центральной области (таб.2).
В возрастном аспекте у 18-тилетних юношей, по сравнению с 17-тилетними, при ПЭС было выявлено увеличение процентной выраженности $\alpha$ - ритма в левой лобной и в правой затылочной областях. Процент $\beta$-ритма снижался в левой лобной области, а в правой затылочной области отмечалось его увеличение. У $\theta$-ритма отмечено снижение процента в левой лобной, в левой и правой центральной и затылочной областях. Снижен процент $\delta$ - ритма в левой и правой центральной областях (таб.2).

Спектральная мощность ЭЭГ. У 17 - и 1 тилетних юношей в спокойном состоянии мощность $\alpha$-, $\beta$-, $\theta$ - и $\delta$-ритма в изучаемых областях показана в табл. 1,2. В напряженном состоянии, по сравнению со спокойным, отмечалось достоверное увеличение мощности $\beta$-ритма в левой лобной области. Мощность же $\theta$-ритма снижалась в правой лобной области, а представленность мощности $\delta$-ритма была высокой в правой затылочной области. У 18-тилетних при напряженном состоянии, по сравнению со спокойным, в мощности $\alpha$ ритма отмечено снижение в правой центральной и затылочной областях.

При ОЭС у 17-тилетних юношей, по сравнению со спокойным состоянием, мощность $\alpha$-ритма снижалась в левой и правой центральной, левой и правой затылочных областях. У $\delta$-ритма отмечалось увеличение в левой затылочной области. У 18-тилетних, по сравнению со спокойным состоянием, мощность $\theta$-ритма снижалась в левой центральной области.

При ПЭС у 17-тилетних мощность $\alpha$-ритма, по сравнению со спокойным, увеличивалась в левой и правой лобной, левой и правой центральной, а также в левой затылочной областях. Мощность $\beta$-ритма также увеличивалась в левой и правой лобной, а также в правой центральной областях. Представленность мощности $\theta$-ритма увеличивалась в левой лобной и в левой и правой центральной и затылочной областях. У $\delta$-ритма отмечено увеличение мощности в правой лобной, левой и правой центральной, левой и правой затылочной областях. У 18-тилетних юношей 
мощность $\delta$-ритма увеличивалась в правой затылочной области, а мощность $\alpha$-ритма снижалась в левой центральной области.

Частотно-амплитудный анализ ЭЭГ. У 17 тилетних юношей в напряженном состоянии, по сравнению со спокойным, по частотным характеристикам было отмечено учащение частоты $\alpha$ - и $\beta$-ритма во всех исследуемых зонах. У 18-тилетних юношей отмечено учащение частоты $\alpha$-ритма в левой и правой лобной и центральной, а частоты $\beta$-ритма в левой и правой лобной и затылочной областях.

У 17-ти летних юношей при ОЭС, по сравнению со спокойным, отмечено снижение частоты $\alpha$-ритма в правой затылочной, а частоты $\theta$-ритма в левой центральной области и левой и правой затылочной областях. У 18тилетних отмечено снижение частоты $\alpha$-ритма в левой и правой лобной и правой центральной областях и снижение частоты $\theta$-ритма в левой и правой лобной областях.

У 17-тилетних юношей при ПЭС, по сравнению со спокойным, отмечено увеличение частоты $\alpha$-ритма в правой лобной, левой и правой центральной и затылочных областях. У 18-тилетних отмечено увеличение частоты $\alpha$-ритма в левой и правой лобной областях.

Таким образом, в частотной характеристике в напряженном состоянии отмечено увеличение $\beta$-ритма во всех исследуемых областях, а $\alpha$-ритма в центрально -затылочной области; при ОЭС отмечено увеличение $\theta$-ритма в центрально -затылочной и снижение $\alpha$-ритма в правой затылочной областях; при ПЭС отмечено доминирование увеличения частоты $\alpha$ ритма во всех исследуемых зонах.

Обсуждение полученных данных. В физиологии постпубертатного развития и стабилизации функций к периоду гражданского совершеннолетия уделяется мало внимания, хотя молекулярно-генетические и фундаментальные исследования последних лет указывают на то, что процесс развития продолжается в течение всей биологической жизни субъекта $[1,7,8,12,14,20,24,27]$.

Современные методы компьютерного анализа биоэлектрической активности мозга позволили вскрыть тончайшие изменения в
ЭЭГ. При этом создавалась возможность проследить состояние корковых областей и корково-подкорковых взаимоотношений, путем определения состояния активирующих и тормозных звеньев неспецифических систем мозга $[2,13,15,21,22]$.

В наших исследованиях установлено, что фоновая ЭЭГ- активность юношей 17 - 18 лет в состоянии физиологического покоя характеризуется доминированием $\alpha$ - и $\beta$-ритмов; по показателям процентной выраженности наблюдается увеличение этого доминирования в каудально-ростральном направлении, выраженность $\delta$ - и $\theta$-ритмов, наоборот, увеличивается в рострально-каудальном направлении.

При обсуждении полученных результатов следует учитывать, что до настоящего времени не сложилось однозначного взгляда на функциональную значимость усиления колебаний в $\delta$-диапазоне ЭЭГ здорового бодрствующего человека. Традиционно увеличение медленноволновой активности ЭЭГ рассматривается как один из наиболее характерных признаков снижения уровня функциональной активности мозга [11], являвшийся свидетельством развития процесса охранительного безусловного торможения, сопровождающимся снижением интеллектуальных и мнестических функций $[13,20]$.

Такая трактовка наших результатов может быть сопоставлена с результатами исследований, в которых показано возрастание мощности $\delta$-диапазона ЭЭГ при эмоциональноотрицательных сценических переживаниях, интерпретируемое авторами как отражение включения мозговых механизмов внутренней защиты $[3,5,8]$.

Полученные нами данные об угнетении $\alpha$ ритма при отрицательном эмоциональном воздействии согласуются с наблюдениями ряда авторов, указывающих на депрессию этого ритма при эмоциональных нагрузках $[9,18]$. Моделирование отрицательного эмоционального состояния приводило одновременно к увеличению выраженности $\theta$-ритма.

Таким образом, можно отметить следующие особенности возрастной динамики ней- 
рофизиологических основ топографического распределения частотно-амплитудных характеристик ЭЭГ-паттернов у юношей в состоянии покоя, а также нейрофизиологических коррелятов этапа переживания ими моделирования различных функциональных состояний (положительных и отрицательных эмоций).

С возрастом (от группы A-17 до группы А18) в состоянии оперативного покоя отмечается умеренное нарастание процентного вклада и спектральной мощности $\alpha$-ритмики во фронтальных и центральных отведениях, более выраженное слева, а также снижение вклада и относительной мощности спектра $\delta$ ритма при смещении частотных характеристик $\alpha$-ритма в сторону $\alpha-1$ диапазона (8-10 Гц), а $\delta$-ритма - в сторону $\beta$-1 диапазона. При этом мощность дельта-ритма несколько снижалась, больше в центральных и задних областях мозга справа.

В ситуации напряженной эмоциональной и психической деятельности в младших возрастных группах типичной реакцией была коактивация по $\alpha$ - и $\beta$-мощностям в лобных и центральных отведениях справа и слева, а также повышение $\theta$-активности - во фронтальных зонах мозга, а $\delta$-активности - в лобных и центральных зонах слева. Такой тип ЭЭГ-паттернов по классификации Е.А. Жирмунской относят к гиперсинхронным [10]. В группах же 17-18 лет при сохранении общей тенденции $\alpha-, \delta$-коактивации в передних зонах мозга отмечалось снижение мощности $\delta$-ритмики в лобных и задних областях, что можно интерпретировать как более "экономичное" мозговое обеспечение напряженной психической деятельности [32,33].

Переживание отрицательных эмоций у юношей 17-18 лет сопровождалось наряду с $\delta$-активацией также повышением спектральной мощности $\alpha$-ритма в лобных отведениях (больше слева), и снижением процентного вклада и спектральной мощности $\delta$-активности, то есть формированием организованного типа ЭЭГ.

В старших же возрастных группах переживание позитивных эмоций сопровождалось избирательной $\alpha$-активацией в лобных и центральных отделах слева при отсутствии выраженной динамики спектральной мощности тета- и $\delta$-ритмов и снижением мощности в $\delta$ диапазоне в лобных и центральных зонах мозга, что в целом согласуется с данными Т.Н.Лапшиной [16] и отражает в большей степени избирательную вовлеченность определенных мозговых структур (более выраженную - слева)

\section{Выводы.}

1.В связи с онтогенетическим развитием выраженность ритмов мозга при различных функциональных состояниях имеют специфическую картину. В напряженном состоянии отмечено увеличение $\alpha$ - и $\theta$-ритма, при ОЭС - $\theta$ - и $\beta$-, при ПЭС- $\alpha$-ритма, в основном, в передней области мозга.

2. У юношей 17 и 18 лет при различных функциональных состояниях в ЭЭГ обнаруживается достоверная смена $\alpha$-ритма на $\theta$ ритм, максимально выраженная при напряженной в умственной нагрузке.

3. Установлено, что у юношей 17 и 18 лет в условиях физиологического покоя, умственной нагрузки, отрицательного и положительного эмоционального состояний интегральные ЭЭГ - характеристики в процентной выраженности, спектральной мощности и в частотной характеристике имеют как выраженное сходство, так и специфические особенности. 


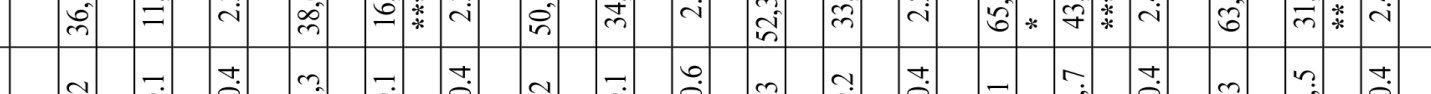

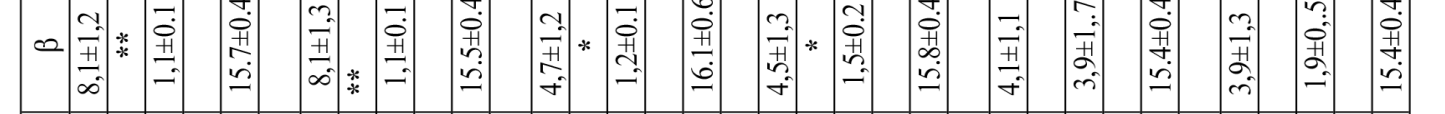

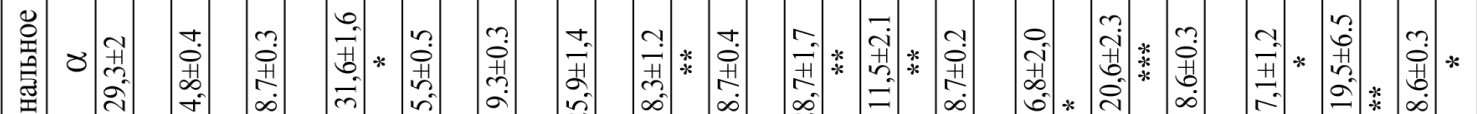

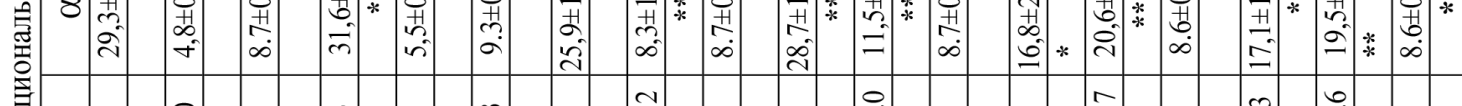

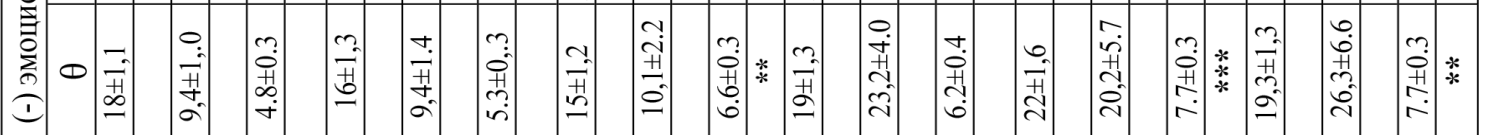
(1)

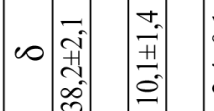

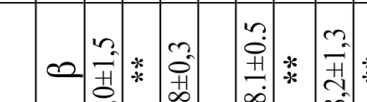
吾

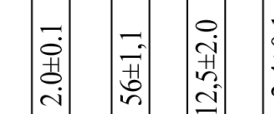

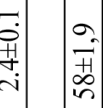
ב⿱艹

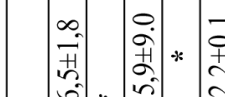
草

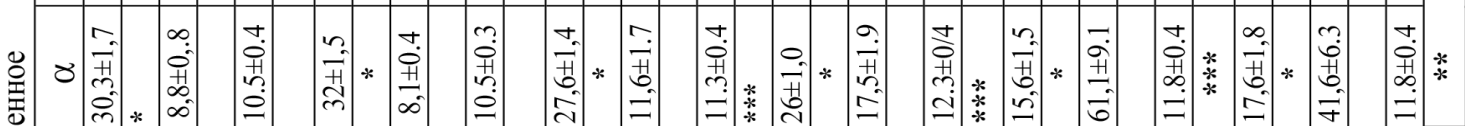

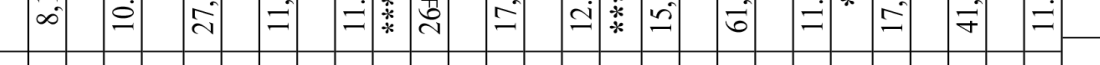

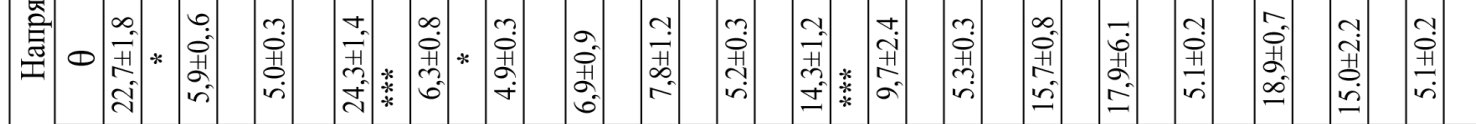

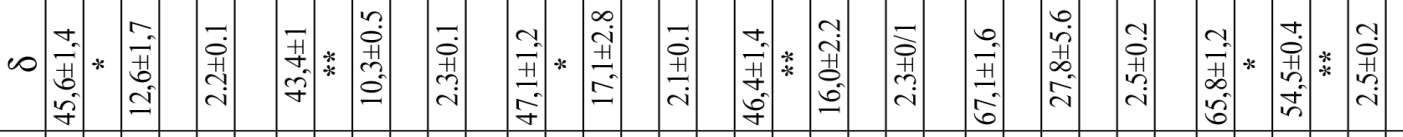

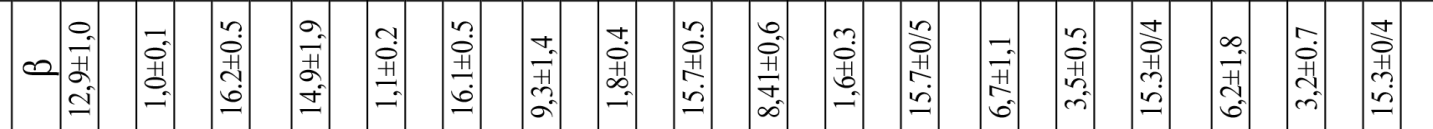

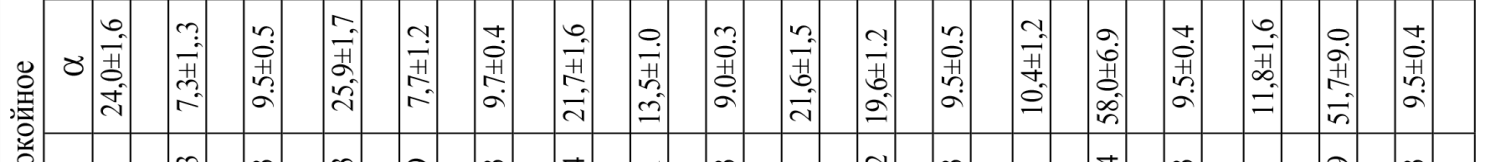

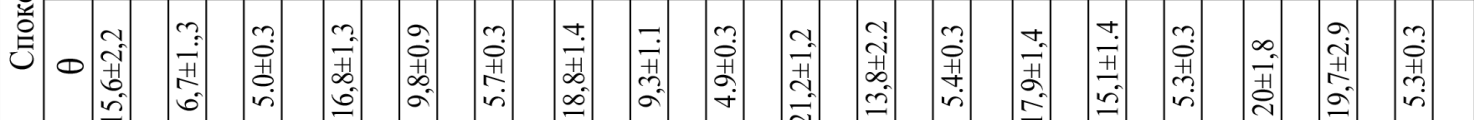

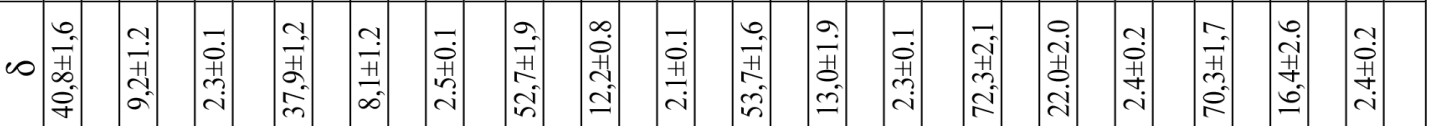

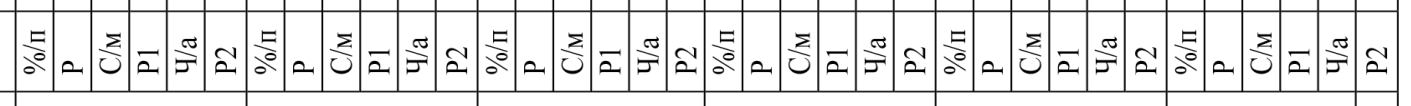

\begin{tabular}{|c|c|c|c|c|c|}
\hline$=$ & 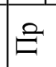 & 5 & $\triangleq$ & $\Rightarrow$ & $\triangleq$ \\
\hline 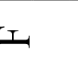 & & \multicolumn{2}{|c|}{$\circlearrowright$} & \multicolumn{2}{|c|}{0} \\
\hline
\end{tabular}




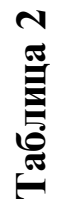

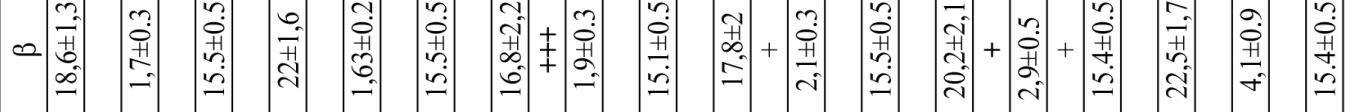

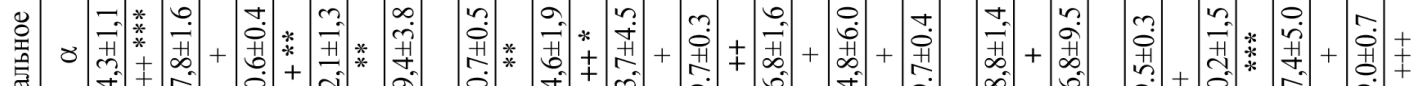
究

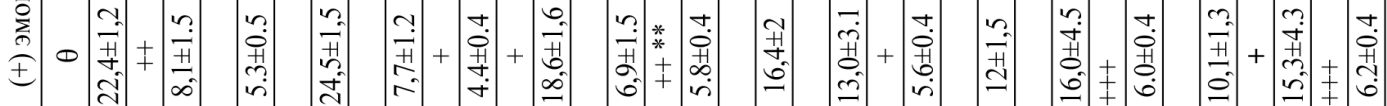

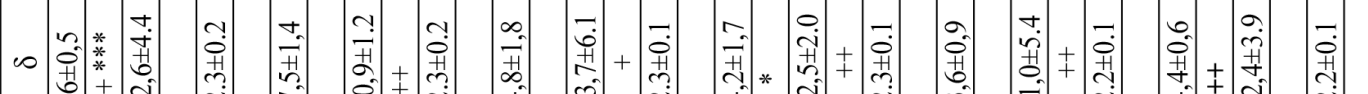

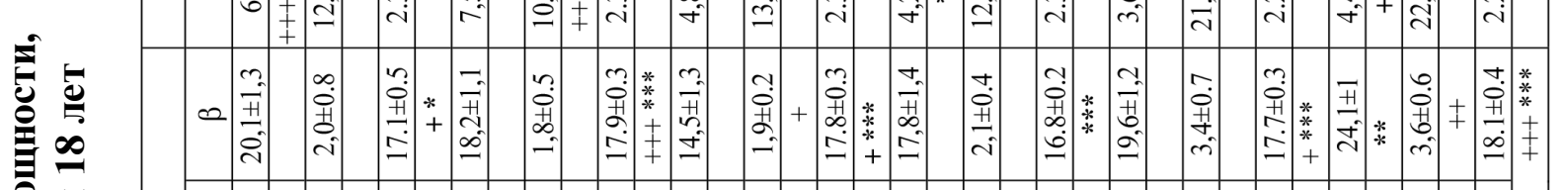

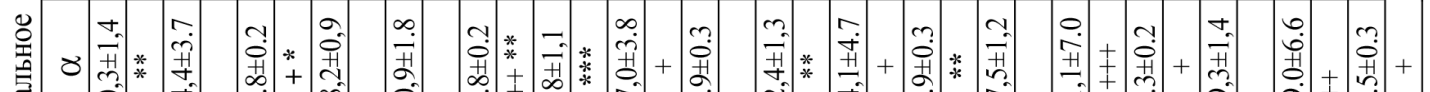

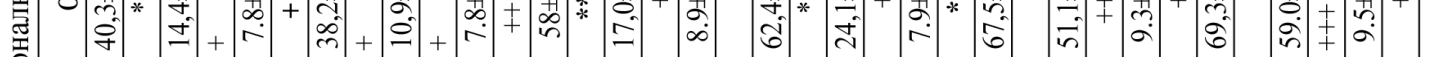

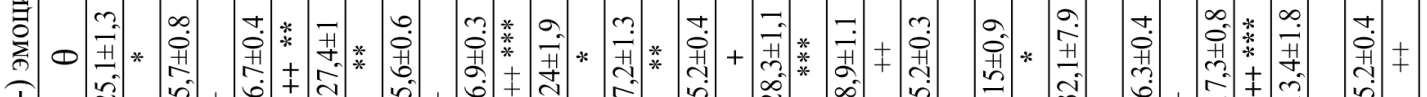
Iิ ป̂.

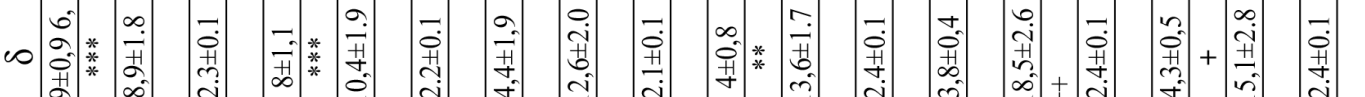

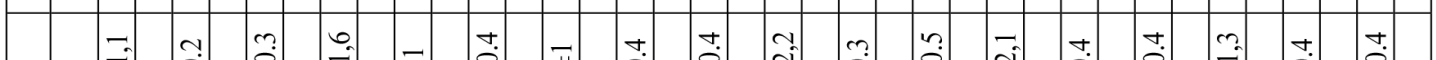

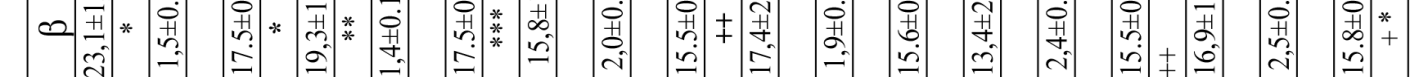

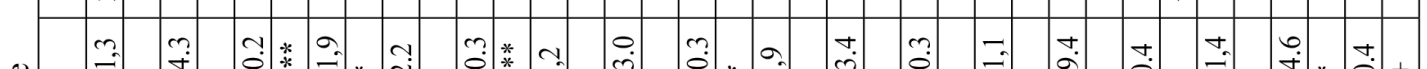

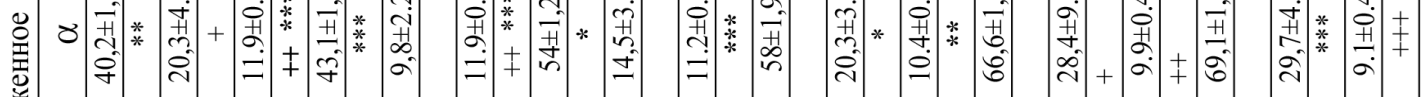

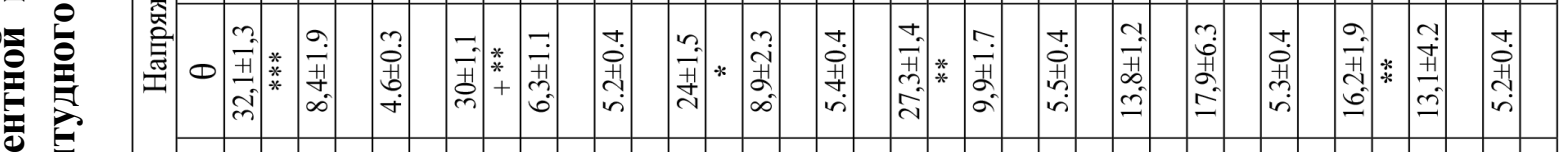

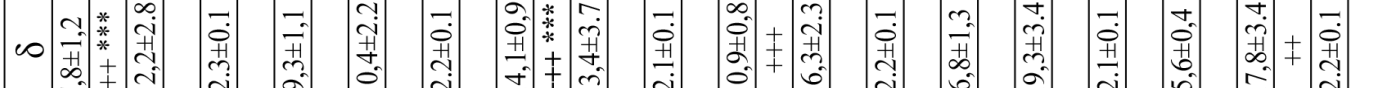

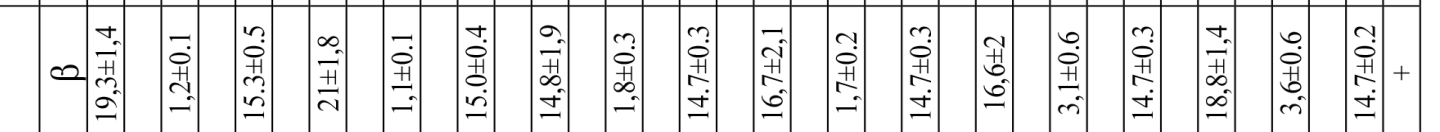

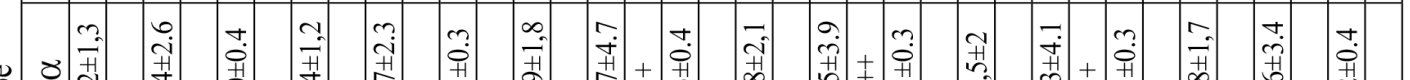

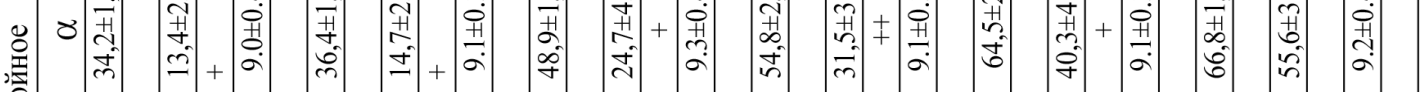

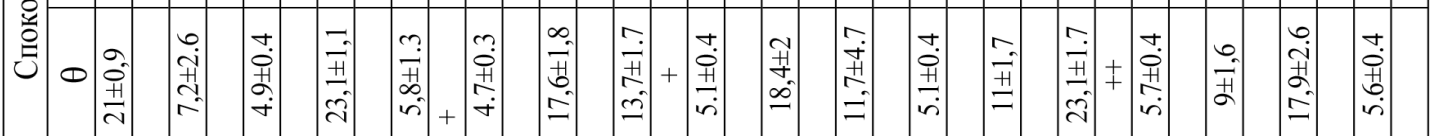

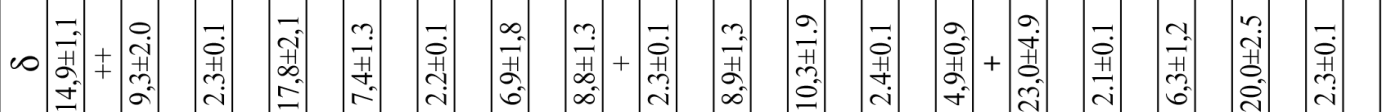

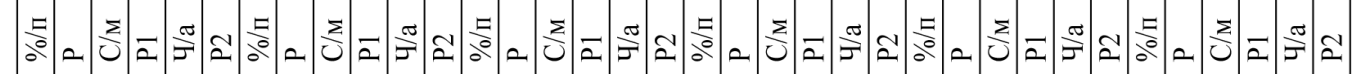

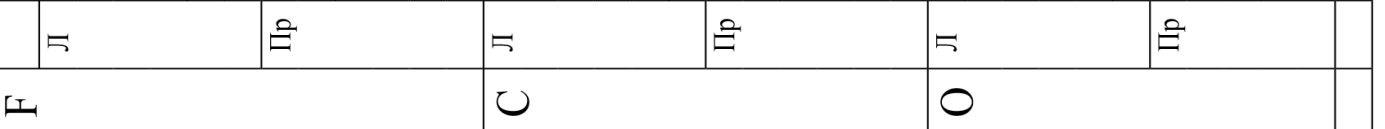




\section{ЛИТЕРАТУРА}

1.Агаева Г.Т. Возрастные особенности биоэлектрической активности головного мозга детей 1-3 лет: Автореф. дисс. канд. мед. наук. Баку, 2005, 20 с.

2. Анохин П.К. Очерки по физиологии функциональных систем. М.: Медицина, 1975, 447 с.

3. Афтанас Л.И., Павлов С.В., Рева Н.В., Варламов А.А. Анализ вызванной синхронизации и десинхронизации ЭЭГ при восприятии угрожа-ющей и положительной эмоциональной информации: влияние фактора, личностной тревожности // Журнал высшей нервной деятельности им. И.П.Павлова., М., 2004, том 54, № 4, c. 473-481.

4.Барвинок А.И., Рожков В.П. Особенности межцентральной координации корковых электрических процессов при умственной деятельности // Физиология человека, 1992, т.18, №3, с. 5-16.

5.Болдырева Г.Н., Жаворонкова Л.А., Шарова Е.В. и др. Межцентральные отношения ЭЭГ как отражение системной организации мозга человека в норме и патологии // Журнал высшей нервной деятельности им. И.П.Павлова, М., 2003, том 53, № 4, с. 391-401.

6. Велиева Г.Д., Электрическая активность головного мозга и корреляция некоторых вегетативных параметров при различных функциональных состояниях мозга у детей 7-14 лет.// Научно-практический журнал "Экспериментальная и клиническая медицина"№1.Труды XVII Международной школы-конференции медиков (Бакуриани, 22-28 января), Тбилиси, 2005с. 27-29.

7. Горбачевская Н.Л., Якупова Л.П. Возрастные особенности формирования ЭЭГ // Новые исследования: альманах. М., 2004, с. 129-130.

8.Данько С.Г., Бехтерева Н.П., Антонова Л.В., Шемякина Н.В. Влияние личного компонента на электроэнцефалографические корреляты индуцированных эмоциональных состояний // Физиология человека, 2004, т.30, №6, с. 122-124.

9.Дмитриева Н.В., Глазачев О.С. Индивидуальное здоровье и полипараметрическая диагностика функциональных состояний организма (системно-информационный подход). М.: Горизонт, 2000, 213 с.

10.Жирмунская Е.М. В поисках объяснения феноменов ЭЭГ. М.: Медицина, 1996, 117 с.

11.Зенков Л.Р. Клиническая электроэнцефалография (с элементами эпилептологии). Таганрог: Изд-во Таганрогского радиотехнического университета.. 2002, 358 с. 12. Казимов А.Г., Мамедов А.М. Изучение особенностей электроэнцефалограммы у здоровых девушек 15 лет, в спокойном состоянии и при различных эмоциогенных воздействиях // Вестник новых медицинских технологий, Тула, 2010, т. XVII, № 4, с. 108-110

13. Каплан А.Я., Финкелькурц А. А., Финкелькурц А.А., Ермолаев В.А. Топографическая вариативность спектральных паттернов ЭЭГ //Физиология человека, 1999, т.25, №2,c. 21-29

14. Князев Г.Г., Слободская Е.Р., Афтанас Л.И., Савина Н.Н. ЭЭГ-корреляты эмоциональных расстройств и отклонений в поведении у школьников // Физиология человека, М., 2002, том 28, № 3, с. 16-22

15. Крапивин С.В., Харитонов А.В., Воронина Т.А. Изменения спектров мощности электроэнцефалограммы при некоторых видах патологии ЦНС и при боли // Вестник РАМН, М., 2004, № 5, с. 25-31

16. Лапшина Т.Н. Психофизиологическая диагностика эмоций человека по показателям ЭЭГ: Автореф. дис. канд. психол. наук. М., 2007, 24 с.

17. Мамедов А.К. Корреляционные показатели электроэнцефалограмм головного мозга при эмоциональном стрессе. Баку: Азернешр, 1979, 89 с.

18. Рябчикова Н.А., Подъячева Е.В., Шульговский В.В. Взаимосвязь межполушарной асимметрии ЭЭГ-активации с эффективностью вероятностно-прогностической деятельности человека / Матер. XVIII съезда физиолог. общества им. И.П.Павлова, Казань, 2001, с.212

19. Семенова Н. Ю. Возрастные особенности показателей спектральной мощности основных ритмов электроэнцефалограммы у детей // Медицинский научный и учебно-методический журнал 2006, № 31, с. 220-237

20. Суворов Н.Б., Зуева Н.Г., Гусева Н.Л. Отражение индивидуально-типологических особенностей в структуре пространственного взаимодействия волн ЭЭГ различных частотных диапазонов // Физиология человека, 2000, т.26, №3, с.60-66.

21. Судаков К. В. Индивидуальная устойчивость к эмоциональному стрессу.; М.: Горизонт, 1998, 267 с.

22. Тумялис А.В., Коренек В.В., Махнев В.П. и др. Индивидуальная частота альфа-активности и переживание положительных и отрицательных эмоций // XXI Съезд Физиологического общества им. И.П.Павлова. Тезисы докладов. М., Калуга: БЭСТ-Принт, 2010, с. 622-623.

23. Умрюхин Е.А., Джебраилова. Т.Д. Коробейникова И.И. Спектральные характеристики ЭЭГ при разной результативности и целенаправленной деятельности студентов в ситуации экзаменационного стресса // Физиология человека, М., 2004, том 30, № 6, с. 28-35.

24. Шерстнев В.В. Концепция системогенеза и современное видение идеи единство процессов развития и интегративной деятельности мозга. " Восьмое Анохинское чтение ", г. Москва. 2007.

25. Яковенко И.А., Черемушкин Е.А. Сопоставление перестроек пространственно-временной организации потенциалов коры больших полушарий мозга человека с частотными характеристиками ЭЭГ при решении когнитивной задачи // Журн. высш. нерв. деят., 1996, т.46, № 3, c. 469-478.

26. Aftanas L.I., Reva N.V., Savotina L.N., Maknev V.P. Neurophysiological correlates of induced discrete emotions in humans: an individually oriented analysis // Neuroscience and Behavioral Physiology. 2006, Vol. 36 (2), p. 119-130. 27. Anokhin A.P., Lutzwnberger W., Birbauter N.Spatiotempozal orqanization of brain dynamics and intelligence: an EEG study in adolescents // Int. J. Psychophysiol. 1999, v. 33, № 3. p 23-38.

28. Cacioppo J.T. Feelings and emotions: role for electrophysiological markers // Biological Psychology, 2004, Vol. 
67, p. 235-243.

29. Koukkou M., Buttmann H. Electroenzephalographische studien der filormationsverar beitung bei akuten und chemaligen schizophrenen patient // Neurotikern und psichiasch Cesunden. Berline, 1984, p. 35-40.

30. Harmony T., Fernandez T., Silva J., Bernal J., DiazComos L., Reys A., Marosi E., Rodrigues M. EEG delta activity: an indicator of attention internal processing during performance of mental tasks // Int. J. Psychophysiol., 1996, v. 24, № 1-2, p. 161-171.

31. Jones N.A., Field T., Davalos M., Hart S. Greater right frontal EEG asymmetry and nonemphathic behavior are observed in children prenatal ly exposed to cocaine // International Journal of Neuroscience, 2004,Vol. 114(4), p. 459-480.

32. Lewis M.D., Lamm C., Segalowitz S.J. et al. Neurophysiological correlates of emotion regulation in children and adolescents // Journal of cognitive neuroscience, 2006, vol. 18, No3, p. 430-443.

33.Shinichi S., Kumano H., Sakano U. Effects of effort and distress coping processes on psychophysiological and psychological stress responses // International Journal of Psychophysiology, 2003, vol. 47, p. 117-128.

\title{
XÜLASə
}

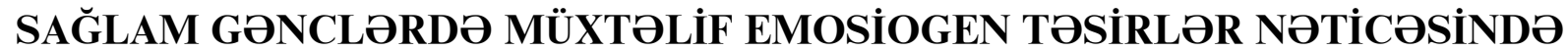 BAŞ VERӘN ELEKTROENSEFALOQRAFIK KORRELYATLAR}

\author{
${ }^{1}$ Kazımov Ө.H., ${ }^{1}$ Cəfərova S.Ş., ${ }^{1}$ Kazımova L.Ә., ${ }^{1}$ Oliyeva D.M., ${ }^{2}$ Həsənov X.İ. \\ ${ }^{1}$ Azarbaycan Tibb Universitetinin Normal fiziologiya kafedrasl, Bakl, Azorbaycan; \\ ${ }^{2}$ Akademik M.Ә.Mir-Qasımov adına Respublika klinik xəstวxanası, Bakı, Azərbaycan
}

Hal-hazırdakı tədqiqat işi yaş aspektində 17-18 yaşlı sağlam gənclərdə, sakit halda və müxtəlif emosiogen təsirlər zamanı EEQ xüsusiyyətlərin öyrənilməsinə həsr olunmuşdur. Göstərilmişdir ki, 17 və 18 yaşında fizioloji sakit şəraitdə, əqli yüklənmədə, mənfi və müsbət emosional vəziyyətlərdə EEQ-nin inteqral xüsusiyyətləri (faizlə təmsil olunma, spektral gücü, tezlik və amplitud analizlərinin göstəriciləri) həm ifadə olunmuş oxşarlıqlara, həmçinin özünəməxsus xüsusiyyətlərə məxsusdurlar. Osasən müxtəlif funksional vəziyyətlərdə alfa ritmlərin, teta ritmlərlə həqiqi əvəz olunması, ən çox ifadə olunması əqli yüklənmnə zamanı gərginlik vəziyyətində aşkar edilir.

Açar sözlər: elektroensefaloqrafiya, sağlam gənclər, emosiogen təsirlər.

\section{SUMMARY}

\section{ELECTROENCEPHALOGRAPHIC CORRELATS AT THE HEALTHY YOUNG MEN IN DIFFERENT EMOCIOGEN INFLUENCES}

\author{
${ }^{1}$ Kazimov A.G., ${ }^{1}$ Djafarova S.Sh., ${ }^{1}$ Kazimova L.A., ${ }^{1}$ Aliyeva D.M., ${ }^{2}$ Hasanov Kh.I. \\ ${ }^{1}$ Department of Normal Physiology Azerbaijan Medical University, Baku, Azerbaijan; \\ ${ }^{2}$ Republican Clinic Hospital named after Akademician M.A.Mir-Gasimov, Baku, Azerbaijan
}

This search is aimed to study EEG characteristic features in the age group of 18 year-old healthy young men in quiet condition and in various emotional impacts. The research has revealed that in the age group of 1718 year-old healthy young men integral EEG characteristics (indicators of representative percentage, spectral intensity, frequency-amplitude analysis) have significant similarities as well as specific distinctions in the conditions of physiological calmness, intellectual tension and negative and positive emotional states. In particular, valid change from various physiological condition alpha rhythms to theta rhythms has been observed mostly in tense contention and intellectual tension.

Keywords: electroencephalography, healthy young men, emotional impacts.

Redaksiyaya daxil olub: 29.06.2015

Çapa tövsiya olunub: 13.07.2015

Rayçi: dos. Sadıxova Z.M. 